\title{
COMPARATIVE EFFECTS ON STORAGE PERIOD OF VARIETIES PINEAPPLE FRUITS
}

\section{*Shah Md. Yusuf Ali', Md. Ahiduzzaman², Sharmin Akhter"1, M Abdul Matin Biswas $^{1}$, Nafis lqbal ${ }^{2}$, Jakaria Chowdhury Onik ${ }^{2}$ and M Hafizur Rahman ${ }^{2}$}

${ }^{1}$ Department of Agricultural Extension, Gazipur Sadar-1701, Bangladesh; ${ }^{2}$ Department of Agro-processing, Faculty of Agriculture, Bangabandhu Sheikh Mujibar Rahman Agricultural University, Salna, Gazipur-1706, Bangladesh

*Corresponding author: Shah Md. Yusuf Ali; E-mail: s.m.yusuf1968@gmail.com

\begin{tabular}{|c|c|}
\hline ARTICLE IN & ABSTRACT \\
\hline $\begin{array}{l}\text { Received } \\
12.11 .2015 \\
\text { Accepted } \\
07.12 .2015 \\
\text { Online } \\
21.12 .2015 \\
\text { Key words } \\
\text { Pineapple } \\
\mathrm{p}^{\mathrm{H}} \text { meter } \\
\text { Refract meter } \\
\text { Weighing balance } \\
\text { Sstorage period }\end{array}$ & $\begin{array}{l}\text { Pineapple is considered as one of the most wanted tropical fruits and it is widely taken for } \\
\text { fresh consumption as well as their flesh and juice are used for preparation of different product } \\
\text { in Agro-processing industries. For such industrial processes, it is important to know the } \\
\text { information of characteristics changes of pineapple during day after storage. Four varieties of } \\
\text { pineapple were collected from different areas of Bangladesh named Honey Queen (H.Q), Giant } \\
\text { Kew (G.K), Asshini and Ghorasal. Some Physico-chemical properties (weight loss, moisture } \\
\text { content, ash and edible portion, pH, TSS, titrable acidity (TA), total sugar, reducing sugar) } \\
\text { biochemical properties (ascorbic acid) and sensorial attributes (color, odor, firmness, } \\
\text { appearances, sweetness and overall acceptability) of pineapple juice were studied during day } \\
\text { after storage. This study examined the Comparison of different varieties of pineapple fruit } \\
\text { characteristics and sensory quality of the pineapple fruits during storage. It was shown that } \\
\text { there was a significant changes between the storage periods in relation to different varieties } \\
\text { of fruits. The firmness of pineapple fruits were in outside and inside to be } 0.21 \text { to } 0.27 \mathrm{~N} / \mathrm{m}^{2} \\
\text { and } 0.06 \text { to } 0.10 \mathrm{~N} / \mathrm{m}^{2} \text {, respectively. The pH values of different varieties were found to be in } \\
\text { the range of } 4.30 \text { to } 4.36 \text {. The highest and lowest sweetness index were estimated to be } \\
36.30 \text { and } 22.15 \text { for Honey Queen and Asshini respectively. The highest and lowest magnitude } \\
\text { of sugar contents of four pineapple varieties were found to be in the range of } 14.16 \text { to } 15.8 \\
\text { mg/ } 100 \mathrm{~g} \text {.The average TSS values were found to be } 15.12 \%, 12.33 \%, 13.14 \% \text { and } 12.95 \% \\
\text { for H.Q., G.K., Asshini and Ghorashal, respectively. The comparative study indicated the } \\
\text { characteristics of different varieties of pineapple changes during after storage. }\end{array}$ \\
\hline
\end{tabular}

To cite this article: Ali SMY, M Ahiduzzaman, S Akhter, M A M Biswas, N Iqbal, J C Onik and M H Rahman, 2015. Comparative effects on storage period of varieties Pineapple fruits. Res. Agric. Livest. Fish. 2 (3): 395-410.

This is an open access article licensed under the terms of the Creative Commons Attribution 4.0 International License

www.agroaid-bd.org/ralf, E-mail: editor.ralf@gmail.com 


\section{INTRODUCTION}

Pineapple (Ananus comosus L. Merr.) has long been one of the most appreciated fruit tropical and subtropical area, because of its attractive flavor and refreshing sugar-acid balance. Pineapple has long been an important cash crop. The climate and the soils of many parts of Bangladesh are suitable for pineapple production. It is widely cultivated in Bandarban, Khagrachari, Moulvibazar, Sylhet, Chittagong, Rangamati Hill tract, Tangail (The daily Star, 2014). At least ninety varieties of pineapple are cultivated in the world. In Bangladesh, however, three varieties of pineapple are mostly grown. The cultivated varieties are Giant Kew (locally Kalandar), Honey Queen (Jaldubi) and Red Spanish (Ghorashal) etc. Apart from this variety, one local variety named "Asshini" (late variety) is grown by a few farmers of Madhupur, Tangail district. About 45,685 ha of land are now 2 under pineapple cultivation with a total production of about 2, 34,865 metric tons. Another local variety named "Ghorashal" is cultivated at Palash upazila in Narsingdi district. In respect of the total production of fruits which grown in Bangladesh it ranks $4^{\text {th }}$ among the major fruits (BBS, 2014). But Bangladeshi pineapples are more juicy and tasty than any other countries (Banglapedia, 2006). The H.Q variety is largely produced in Sylhet, Habigang, Moulviganj, Kamalgonj and Satgaon with coverage of 4454.00 ha (The Daily Star, 2014). However, the Honey Queen is the small fruit compared to other varieties which has a necessary demand. Rabon and Borab areas of Palash, Narsingdi district are found that farmers of the area are involved themselves in pineapple cultivation and they raise a new orchard with their own initiative (Banglapedia, 2006).

Pineapple is used for the preparation of alcohol, calcium citrate, citric acid, vinegar, oxalic acid, pineapple gum and flavor. It is a good source of vitamin A, B \& C, carotene, ascorbic acid and is rich in calcium, phosphorus, magnesium, potassium and iron (USDA Nutrient data base 2008 and Rashid et.al 1987). There are some of the many health benefits of eating ripens pineapples such as packed with vitamins and minerals, prevents cough and colds, strengthens bones, keeps gums healthy, lowers risk of macular degeneration, alleviates arthritis, improves digestion etc. (USDA nutrient database 2008). Besides, it is also a source of bromelin, a digestive enzyme (Lodh et al., 1973). Various food items like squash, syrup, jelly, etc. are prepared from pineapple. Its juice is helpful for healing fever, jaundice, influenza and cold, among other ailments (USDA nutrient database 2008). Diversified uses of pineapple have also led to develop many fruit processing industries both in developed and developing countries including Bangladesh. However, the processing characteristics of pineapple such as different physio- chemical properties are not properly studied for the different varieties grown in Bangladesh. That's why it is necessary to know the different properties of different varieties of pineapple. This study was conducted to find out the physio- chemical characteristics and sensory quality of the different pineapple varieties during days after storage. The objective of the research was to study the effect of storage period of pineapple varieties on physico-chemical properties and sensorial attributes and to make a comparison of different properties among the varieties of pineapple.

\section{MATERIALS AND METHODS}

\section{Experimental materials}

The experiment was carried out in the laboratories of the Department of Agro-Processing, Bangabandhu Sheikh Mujibur Rahman Agricultural University, Gazipur, during the period from July, 2014 to June 2015. The laboratory of Agro-Processing department was used for chemical analysis of fruits and the laboratory of PostHarvest Technology division, BARI was used for preliminary studies.

\section{Materials used for this experiment}

The materials used for the experiment were the freshly harvested pineapple fruits of the variety Giant Kew, Honey Queen, Asshini and Ghorashal. The fruits Giant Kew and Asshini were collected from field of the growers of Gachabari village and Jalchittra market, Madhupur Upazila in Tangail district, Honey queen variety was collected from Sylhet and Ghorashal variety was collected from Palash upazilla, Narsinghdi district. The fruits of optimum maturity stage were identified and harvested in the morning hours and immediately transferred with careful handling and placed to the Department of Agro-Processing laboratory, Bangabandhu 
Sheikh Mujibur Rahman Agricultural University, Gazipur. The fruit was kept for twelve days for storage to analyze the different properties of fruits at different days after storage. The experimental pineapples were loaded immediately in a recognized wooden box with utmost care and covered with a polythene paper to protect the fruits from direct sunlight. For transport fruits were placed on leaves with crowns and layer to layer to decrease mechanical damage. Then the fruits were immediately transferred to the Agro-processing Laboratory.

\section{Pineapple Storage for experimental use}

The different varieties of pineapple were placed in the Agro-Processing laboratory at the room temperature located at the floor. The floor was covered with newspaper. Very little information available in Bangladesh on physic- chemical changes, shelf life changes during storage and ripening. Storing at room temperature will increase the acidity level of the pineapple, but will not improve sweetness.

\section{Sample preparation}

Pineapple were weighed using a top loading balance (Salter Model, Japan), the weight of the samples were determined and juice extraction from samples were performed according to the method described by Lim (1985). The crown and stem portions were removed and the skin were peeled by using knife. After that the fruits were sliced and the fruit slices were pressed using a blender (Jensons Lab, Japan) into paste for one to two minutes to get the pineapple juice and then the juice was collected. The mixture was then filtered through a muslin cloth Juice was collected is similar way for other varieties and the extracts were then stored in a normal room temperature.

The extracted juice was used for present study. Standard procedure was used for determining the different characters. The data obtained from different pineapples samples were recorded. The experimental treatments were as follows:

Table1. Treatments of the study

\begin{tabular}{|c|c|c|c|c|c|c|c|c|c|c|c|c|}
\hline \multirow{3}{*}{$\begin{array}{l}\text { Variety } \\
\text { H.Q. }\end{array}$} & \multicolumn{12}{|c|}{ Days after storage ( DAS) } \\
\hline & \multicolumn{3}{|c|}{$\mathrm{D}_{0}$} & \multicolumn{3}{|c|}{$\mathrm{D}_{4}$} & \multicolumn{3}{|c|}{$\mathrm{D}_{8}$} & \multicolumn{3}{|c|}{$D_{12}$} \\
\hline & T1 & T2 & T3 & T1 & T2 & T3 & T1 & T2 & T3 & T1 & T2 & T3 \\
\hline G.K. & T1 & T2 & T3 & $\mathrm{T} 1$ & T2 & T3 & T1 & T2 & T3 & T1 & T2 & T3 \\
\hline Asshini & T1 & T2 & T3 & T1 & T2 & T3 & T1 & T2 & T3 & T1 & T2 & T3 \\
\hline Ghorasal & $\mathrm{T} 1$ & T2 & T3 & T1 & T2 & T3 & T1 & T2 & T3 & T1 & T2 & T3 \\
\hline
\end{tabular}

N.B. D0: 0 DAS, D 4 : DAS, D8: 8DAS, D12: 12DAS and T1, T2 and T3 are recap

For experiment, fifty six numbers of different varieties of pineapple were taken. For experiment three number of each variety fruit were taken. Table 1 show that there were forty eight number of different varieties of pineapple were taken for physio- chemical parameters and total eight number of varieties were kept for shelf life observation after $0,4,8$ and 12 DAS.

\section{Analyses of physical properties}

The effect of different postharvest treatments on shelf life and the quality changes of pineapples storage were studied here. The data were collected on different characteristics of sensory evaluation and analyzed. The following parameters were studied.

\section{Percent weight loss of fruit}

Per weight loss was calculated by using the following equation:

Percent weight loss $(\% \mathrm{WL})=\frac{I W-F W}{I W} \times 100$

Where,

$\mathrm{WL}=$ Percent total weight loss, IW = Initial weight of fruits $(\mathrm{kg}), \mathrm{FW}=$ Final weight of fruits $(\mathrm{kg})$ 


\section{Moisture content}

Moisture content was determined by using the Standard Official methods of Analysis (AOAC 1990). This involved drying to a constant weight at $105^{\circ} \mathrm{C}$ at calculated moisture as the loss in weight of the dried samples. The crucible was thoroughly washed and dried in an oven at $100^{\circ} \mathrm{C}$ for $30 \mathrm{~min}$ and allowed to cool inside desiccators. After cooling they were weighed using a weighing balance and recorded as $\mathrm{W}_{1}$, then 2.0 $\mathrm{gm}$ of the finely ground samples were put into crucibles and weighed to determine the value of $W_{2}$. Thereafter, the sample and crucible were placed inside the oven and dried at $105^{\circ} \mathrm{C}$ for 4 hour, then cooled \& weighed at the same temperature for 30 min until constant weights were obtained to get $W_{3}$.

The percent moisture content was calculated using the following equation:

$$
\% \text { moisture content }=\frac{w_{1}-w_{2}}{w_{1}-w_{3}} \times 100
$$

Where,

$\mathrm{W}_{\mathbf{1}}=$ Initial pineapple sample weight with crucible

$\mathrm{W}_{\mathbf{2}}=$ Final pineapple sample weight with crucible

$W_{3}=$ Initial weight of empty crucible

\section{Determination of total ash}

Total ash content of the sample was determined by incineration in a muffle furnace, as described by $A O A C$ based on the vaporization of water and volatile with being organic substances in the presence of Oxygen in the air to $\mathrm{CO}_{2}$ at a Temperature of $550^{\circ} \mathrm{C}$ (Dry ash). About $1.0 \mathrm{gm}$ of finely ground dried sample was placed in a porcelain crucible and incinerated at $550^{\circ} \mathrm{C}$ for 6 hour in a muffle in furnace. The ash was cooled in a desiccators and weighed. The percentage of ash content in the sample was calculated.

$$
\text { Ash content }(\%)=\frac{\text { wt.ofash }}{\text { Total wt.of sample }} \times 100
$$

\section{Edible portion (\%)}

Initially the total weight of fruit without crown was weighed by using a balance. Then the fruit was peeled by using sharp knife and the central core was removed and the remaining fruit pulp was weighed. Finally the percentage of edible portion of the fruit was measured with the following equation (Ranganna 1994).

$$
\text { Edible portion of fruit }(\%)=\frac{\text { wt of edible portion }}{\text { Total wt.of fruit }} \times 100
$$

\section{Shelf life}

The shelf life was recorded by counting the days required to attain the last stage of ripening, but the fruit remaining still ready for marketing (Ranganna 1994).

\section{Firmness Test}

The firmness of pineapple fruit can be determined (outside and inside) by measuring penetration force using an Instron Universal testing machine.

\section{Analyses of Chemical properties}

\section{pH measurement of pulp juice}

The $\mathrm{pH}$ of pineapple juice samples was evaluated with the Sartorius Professional Meter PP-50. The measurement was a mean value of triplicates.

\section{Determination of TSS}

The Total soluble solids of pineapple juice samples were measured using digital refractometer Digit at 19$20^{\circ} \mathrm{C}$. Results were reported as degrees Brix. 
Table 3. Effects of physical properties of different varieties of pineapple during day after storage.

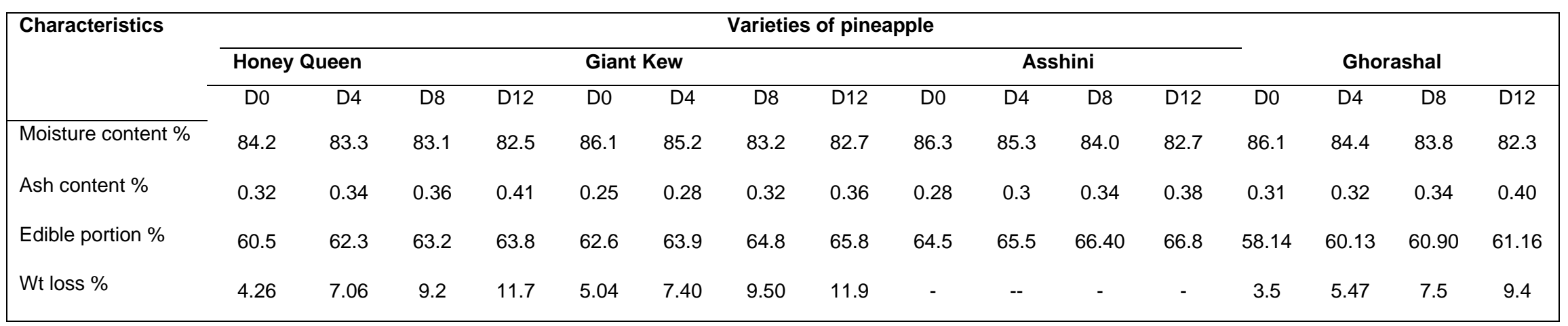

Table 3 shows the physical properties such as ash content (\%) and the edible portion (\%) of different varieties of pineapple are increased during increased storage time. But the moisture content of fruits are decreased during increased storage period. 


\section{Vitamin C estimation}

Ascorbic acid content was determined to the method of Ranganna (1994) by using 2,6-DichlorophenolIndophenol Visual Titration Method. i) 3\% metaphosphoric acid $\left(\mathrm{HPO}_{3}\right)$ : It was prepared by dissolving $50 \mathrm{~g}$ HPO3 in distilled water and volume make up to $1000 \mathrm{ml}$.ii) Ascorbic acid standard: Weigh accurately $100 \mathrm{mg}$ of L-ascorbic acid and make up to $100 \mathrm{ml}$ with $3 \%$ HPO3. Dilute $10 \mathrm{ml}$ to $100 \mathrm{ml}$ with $3 \% \mathrm{HPO} 3(1 \mathrm{ml}=0.1 \mathrm{mg}$ of ascorbic acid).iii) Dye Solution: $0.0525 \mathrm{gm}$ of sodium bcarbonate dissolve in hot glass distilled water and add $0.0625 \mathrm{gm}$ of 2,6 dichlorophenol- indophenols cool and make up $250 \mathrm{ml}$ ( Lane and Eynon 1923). The following steps were followed for estimation of ascorbic acid:

a) Standardization of dye solution: Five $\mathrm{ml}$ of standard ascorbic acid solution was taken in a conical flask and $5 \mathrm{ml}$ of metaphosphoric acid $\left(\mathrm{HPO}_{3}\right)$ solution was added to it and shaken. A micro burette was filled with the dye solution and the mixed ascorbic acid solution was titrated with dye where appearance of pink color indicated the end point, which persisted at least15 seconds. The milliliters of dye solution required to complete the titrations recorded.

Dye factor was calculated using of the following formula-

Dye factor $=\frac{1}{\text { Titre }}$

b) Preparation of sample: Ten grams of fresh pulp was homogenized with $50 \mathrm{ml}$ of $3 \%$ metaphosphoric acid solution in a blender machine. After blending it was filtered and transferred to a $5000 \mathrm{ml}$ volumetric flask and was made up to the mark with $3 \%$ metaphosphoric acid.

c) Titration: Ten $\mathrm{ml}$ of pulp extracted sample was taken in an aliquot and titrated with dye solution (2, 6dichlorphenol-Indophenol) till pink color was appeared which persisted at least 15 seconds. The titration was replicated thrice for each time.

The ascorbic acid content of the sample was calculated by sing the following formula-

Vitamin C content $(\mathrm{mg} / 100 \mathrm{~g})=\frac{T \times D \times V_{1}}{V_{2} \times W} \times 100$

Where,

$\mathrm{T}=$ Titer

$\mathrm{D}=$ Dye factor

$\mathrm{V}_{1}=$ Volume made up

$V_{2}=$ Volume of extract taken for estimation

$\mathrm{W}=$ Weight of sample taken for estimation

\section{Titrable acidity}

The titratable acidity, expressed in \% of citric acid was determined by the titrametric method (Ranganna 1994). The following reagents were used for the determination of titrable acidity.

\section{Reagent preparation:}

Dissolve $0.40 \mathrm{gm}$ of $\mathrm{NaOH}$ in water, and volume make up $100 \mathrm{ml}$. Dissolve $1.00 \mathrm{gm}$ of phenolphthalein indicator in ethanol and volume make up $100 \mathrm{ml}$.

\section{Extraction of pineapple juice}

$10 \mathrm{~g}$ of fruit pulp was taken in $100 \mathrm{ml}$ beaker and homogenized with distilled water in blender. The blended materials were than filtered and transferred to a $250 \mathrm{ml}$ volumetric flask and the volume was made up to the mark with distilled water. 


\section{Procedure}

$10 \mathrm{ml}$ of pulp solution was taken in a $100 \mathrm{ml}$ conical flask. Two or three drops of phenolphthalein indicator were added and then the conical flask was shaken vigorously. It was then filtrated immediately with $0.1 \mathrm{~N}$ $\mathrm{NaOH}$ solution from a burette till a permanent pink color was appeared. The titration was done for three times. The percentage of titrable acidity in fruit pulp was calculated by using following formula-

Titrable acidity $(\%)=\frac{T \times N \times V_{1} \times E}{V_{2} \times W \times 1000} \times 100$

Where,

$\mathrm{T}=$ Titre

$\mathrm{N}=$ Normality of $\mathrm{NaOH}$

$\mathrm{V} 1$ = Volume made up

$\mathrm{E}=$ Equivalent weight of acid

V2 = Volume of extract taken for estimation

$\mathrm{W}=$ Weight of sample taken for estimation

\section{Determination of total sugars}

\section{Reagents preparation}

Fehling"s solution (A) Dissolve $69.28 \mathrm{gm}$ of copper sulphat (CuSO4.5H2O) in water, make up volume $1000 \mathrm{ml}$. Fehling"s solution (B) Dissolve $346 \mathrm{gm}$ of Potassium Sodium Tartrate and $100 \mathrm{gm}$ of $\mathrm{NaOH}$ in water, make up volume $1000 \mathrm{ml}$.

\section{Methylene blue indicator}

Dissolve $1 \mathrm{gm}$ of Methylene blue in $100 \mathrm{ml}$ of water. $10 \%$ lead acetate solution: Dissolve $10 \mathrm{gm}$ of lead acetate in water and volume make up $100 \mathrm{ml}$.

10\% Potassium Oxalate solution: Dissolve $10 \mathrm{gm}$ of Potassium Oxalate in water and volume make up $100 \mathrm{ml}$. Standard invert sugar solution: Weight accurately $0.25 \mathrm{gm}$ of glucose in water and volume make up $100 \mathrm{ml}$. $1 \mathrm{~N} \mathrm{NaOH}$ solution: Take $40 \mathrm{gm}$ of $\mathrm{NaOH}$ in water volume make up $1000 \mathrm{ml}$. The Standardization of Fehling"s solution could be calculated according to following procedure (Ranganna, 1994).

a) Standardization of Fehling's solution: Fifty $\mathrm{ml}$ of both Fehling"s solution A and Fehling"s solution B were mixed together in a beaker. Ten millimeter of the mixed solution was pipette into a $250 \mathrm{ml}$ conical flask and $25 \mathrm{ml}$ distilled water was added to it standard sugar solution was taken in a burette. The conical flask containing mixed solution was heated on a hot plate. When the solution began to boil, three drops of ethylene blue indicator solution was added to it without removing the flask from the hot plate. Mixed solution was titrated by standard sugar solution.

The end point was indicated by depolarization of the indicator. Fehling"s Factor was calculated by using the following formula-

Factor for Fehling solution $=\frac{\text { Titre } \times 2.5}{1000}$

b) Preparation of sample: Twenty gram of fresh pineapple fruit pulp was taken in a $100 \mathrm{ml}$ beaker an then it was transferred to a blender machine and homogenized with distilled water. After blending it was made up to the mark with distilled water. The pulp solution was filtered. One hundred milliliter of filtrate was taken in a $250 \mathrm{ml}$ volumetric flask. Five milliliter of $45 \%$ neutral lead acetate solution was added to it and then shaken and waited for 10 minute. Five milliliter of $22 \%$ potassium oxalate solution was further added to the flask and the volume was made up to the mark with distilled and filtered.

\section{Reducing sugar content (\%)}

$10 \mathrm{~mL}$ of mixed Fehling"s solution was taken in a $250 \mathrm{ml}$ conical flask and $50 \mathrm{~mL}$ distilled water was added to it. Filtrated pulp solution was taken in a burette. Conical flask containing the mixed Fehling"s solution was heated on a hot plate. Three to five drops of methylene blue indicator were added to the flask when 
boiling started, and titrate with solution taken in the burette. The end point was indicated by decolourization of indicator. Percentage of reducing sugar was calculated according to the following equation:

Reducing sugar content $(\%)=\frac{F \times D}{T \times W} \times 100$

Where,

$\mathrm{F}=$ Fehling"s factor, $\mathrm{D}=$ Dilution, $\mathrm{T}=$ Titre and $\mathrm{W}=$ Weight or volume of the sample

\section{Titration of total invert sugar}

Fifty milliliter purified solution (filtrate) was taken in a $250 \mathrm{ml}$ conical flask. Five gram citric acid and $50 \mathrm{ml}$ distilled water were added to it. The conical flask containing sugar solution was boiled for inversion of sucrose and finally cooled. Then the solution was transferred to a $250 \mathrm{ml}$ volumetric flask and neutralized by $1 \mathrm{~N} \mathrm{NaOH}$ using phenolphthalein indicator. The volume was made up to the mark with distilled water. Then the mixed Fehling"s solution was titrated using similar procedure followed as in case of invert sugar (reducing sugar) mentioned earlier. The percentage of total invert sugar was calculated by using the formula used in case of reducing sugar.

\section{Non-reducing sugar}

Non-reducing sugar was estimated by subtracting reducing sugar from total invert sugar as following:

$\%$ non-reducing sugar $=\%$ total invert sugar $-\%$ reducing sugar.

\section{Estimation of total sugar}

Total sugar was estimated by adding the reducing sugar and non-reducing sugar as following:

$\%$ total sugar $=\%$ reducing sugar $+\%$ non-reducing sugar

Determination of the sweetness index

The sweetness index can be calculated according to the (Ranganna, 1994) formula

SI $=\frac{\text { Total so luble solid }}{\text { Acidity }}$

\section{RESULTS AND DISCUSSIONS}

Physical characteristics of different varieties of pineapple

Results on physical changes of pineapple as obtained at 4 days interval from initial stage to 12 DAS for the present experiment were presented and discussed below:

\section{General Physical Parameters}

\section{Weight loss}

Table 2. Effects of weight loss during days after storage

\begin{tabular}{|c|c|c|c|c|c|c|c|c|c|c|c|c|c|c|c|c|}
\hline \multirow{3}{*}{$\begin{array}{l}\text { Characteri } \\
\text {-stics }\end{array}$} & \multicolumn{16}{|c|}{ Physical parameters at different varieties of pineapple at DAS } \\
\hline & \multicolumn{4}{|c|}{ Honey queen } & \multicolumn{4}{|c|}{ Giant Kew } & \multicolumn{4}{|c|}{ Asshini } & \multicolumn{4}{|c|}{ Ghorashal } \\
\hline & $\mathrm{D}_{0}$ & $\mathrm{D}_{4}$ & $\mathrm{D}_{8}$ & $D_{12}$ & $D_{0}$ & $\mathrm{D}_{4}$ & $\mathrm{D}_{8}$ & $\mathrm{D}_{12}$ & $\mathrm{D}_{0}$ & $\mathrm{D}_{4}$ & $\mathrm{D}_{8}$ & $\mathrm{D}_{12}$ & $\mathrm{D}_{0}$ & $\mathrm{D}_{4}$ & $\mathrm{D}_{8}$ & $D_{12}$ \\
\hline $\begin{array}{l}\text { Fruit } \\
\text { weight with } \\
\text { crown }(\mathrm{g})\end{array}$ & 820 & 710 & 625 & 520 & 1.85 & 1780 & 1685 & 1500 & 2000 & 1980 & 1685 & 1600 & 790 & 631 & 525 & 425 \\
\hline $\begin{array}{l}\text { Diameter } \\
(\mathrm{cm})\end{array}$ & 35 & 34 & 34 & 33 & 35 & 34 & 32 & 29 & 36 & 33 & 32 & 29 & 33.3 & 32 & 30 & 28.9 \\
\hline $\begin{array}{l}\text { Length } \\
(\mathrm{cm})\end{array}$ & 11 & 9 & 8.6 & 8.2 & 13.5 & 13 & 14 & 12 & 15 & 14 & 14 & 12 & 10 & 8.6 & 8.16 & 8.9 \\
\hline
\end{tabular}




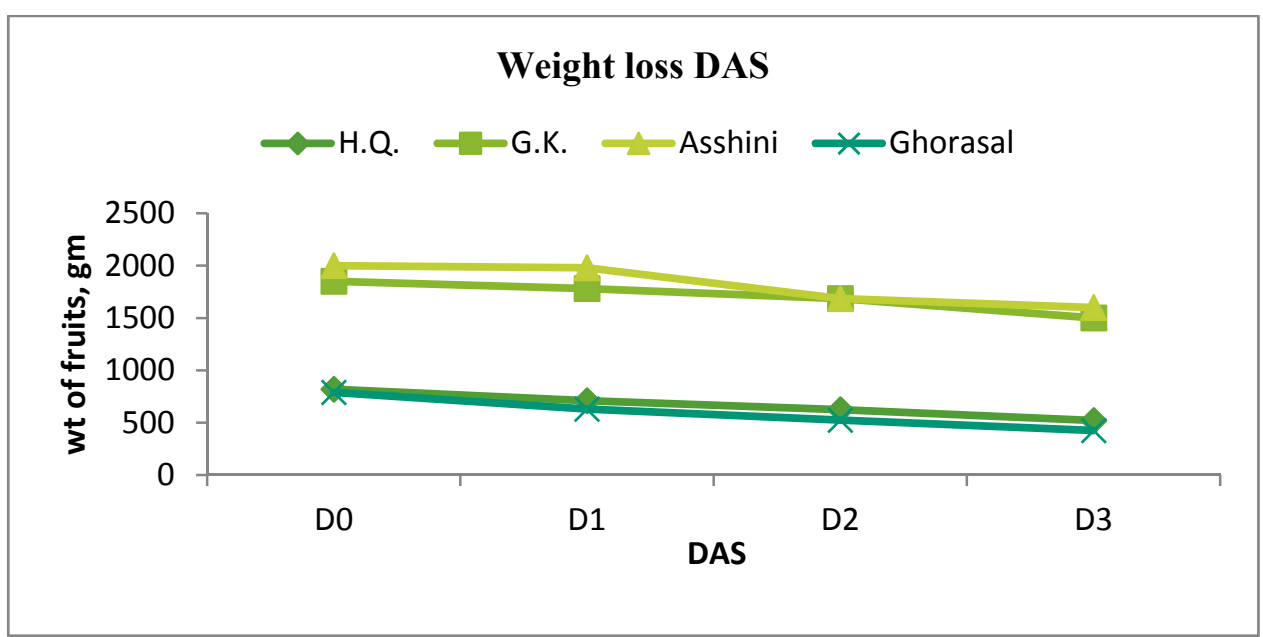

Figure 1. Effects of different varieties of pineapple on weight loss at different DAS

The Figure 1 showed that the weight loss was slightly decreased during the storage period of different verities. It was observed that the higher wt. of Asshini and G.K., so the wt. losses trends above the other H.Q. and Ghorasal variety. It was observed that there was a slightly decreased between D0 to D1 but rapidly decreased between D1 to D2. The other parameters length and diameters are almost same condition.

\section{Moisture content}

It was observed that fig.2.the moisture content decreased with the increase during storage period. Moisture content of pineapple pulp decreases from 82.5 to $84.2 \%$ for H.Q., $82.7 \%$ to $86.1 \%$ for G.K., 82.7 to $86.3 \%$ for Asshini and 82.30 to $86.19 \%$ for Ghorashal during the storage period of 0 to 12 DAS. The highest decrease in moisture content was found $3.7 \%$ in Asshini variety and lowest decrease in moisture content was found $1.4 \%$ in H.Q. variety. These values are approximately similar to those values as found by Hasan (1980) who found $87.30 \%$ and $84.50 \%$ in H.Q. and G.K., respectively.

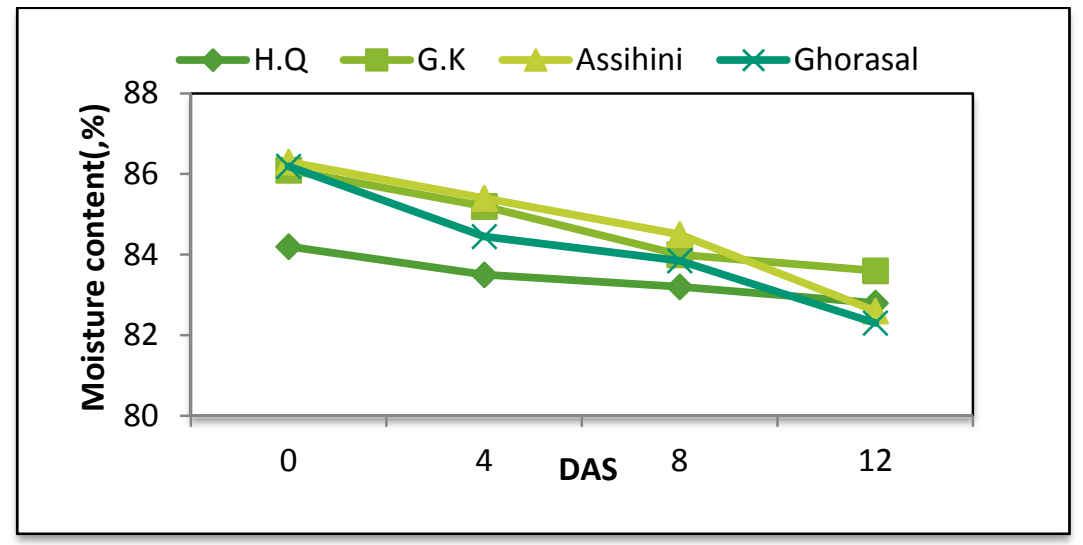

Figure 2. Moisture content (\%) of pineapple juice of different varieties at different DAS.

\section{Ash content (\%)}

It was observed that the ash slightly increased with the increase in storage time. Ash in the pulp of varieties of pineapple were found to be in the range of 0.32 to $0.41 \%$ (Honey queen), 0.25 to $0.36 \%$ (Giant Kew), 0.28 to $0.38 \%$ (Asshini) and 0.31 to $0.40 \%$ (Ghorashal) during the storage of 12 days. These values are very similar to those values as found by Das and Medhi (1996) who got found ash content of $0.23 \%$ to $0.50 \%$ fresh weight (fw) pineapples which is very similar to experiment variety. 


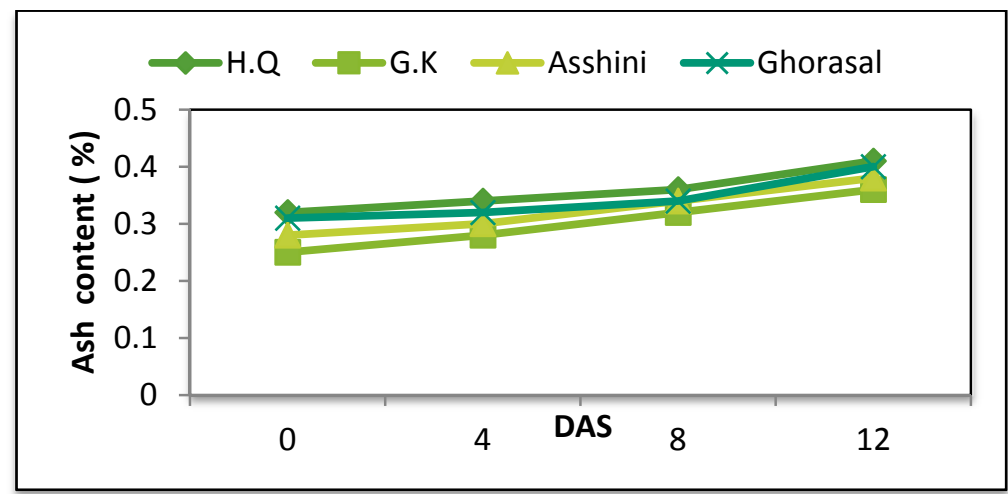

Figure 3. Ash content (\%) of different varieties of pineapple at different DAS

\section{Edible portion}

The edible portion of fruits was significantly affected with days after storage (Fig.4). The edible portion of H.Q, G.K., Asshini and Ghorashal varieties were 60.5 to $63.86 \%, 62.60$ to $65.80 \%, 64.56$ to $66.80 \%$ and 58.14 to $61.16 \%$ increased respectively during the storage period of 0 to 12 days. It was observed that at the $12^{\text {th }}$ day of storage, the highest $(66.8 \%)$ values of Asshini were recorded. The trend of increasing edible portion was similar with the varieties when Asshini was top and Ghorashal was smaller producing the edible portion. Ahmed and Rahman (1974) studied that the edible portion of pineapple fruits contained $67.70 \%$ of their whole weight.

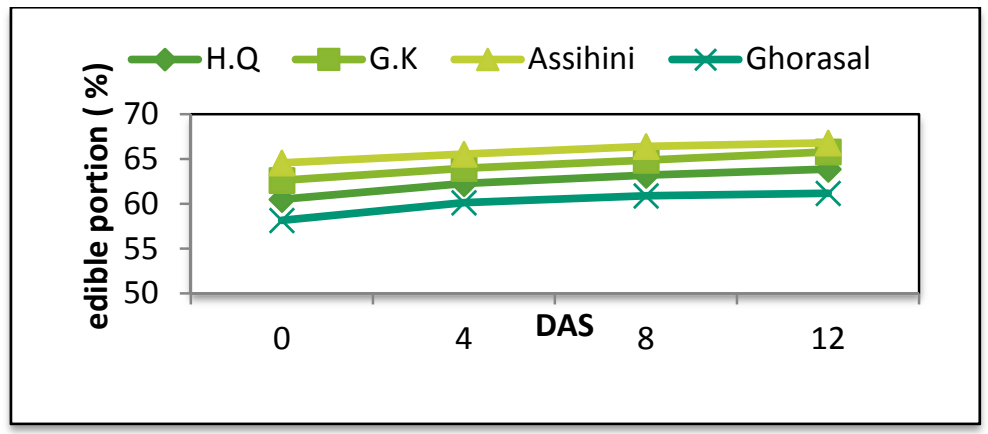

Figure 4. Effects of different varieties of pineapple of edible portion (\%) at different DAS

\section{Shelf life}

Shelf life of pineapple fruits was calculated by counting the number of days required to ripen fully with retained optimum marketing and eating qualities. It was shown that the effective shelf life of pineapple which acceptable till 8 DAS as eating but at 12 DAS were not quality for consumption. It also showed that the peel and crown of the pineapples were accepts but their core, inter pulp are likes slightly acceptable but the juice color are not quality acceptable at 12 DAS.

\section{Color}

It has been shown that the peel color of pineapple was changed from green color to bright yellow which increased as the duration of storage progressed. The change in color during storage might be increase in carotene pigments of the pulp caused by enzymatic oxidation and photo degradation due to series of physical and chemical changes like the breakdown of chlorophyll and increase pigments of the pulp caused by enzymatic oxidation. 
Color

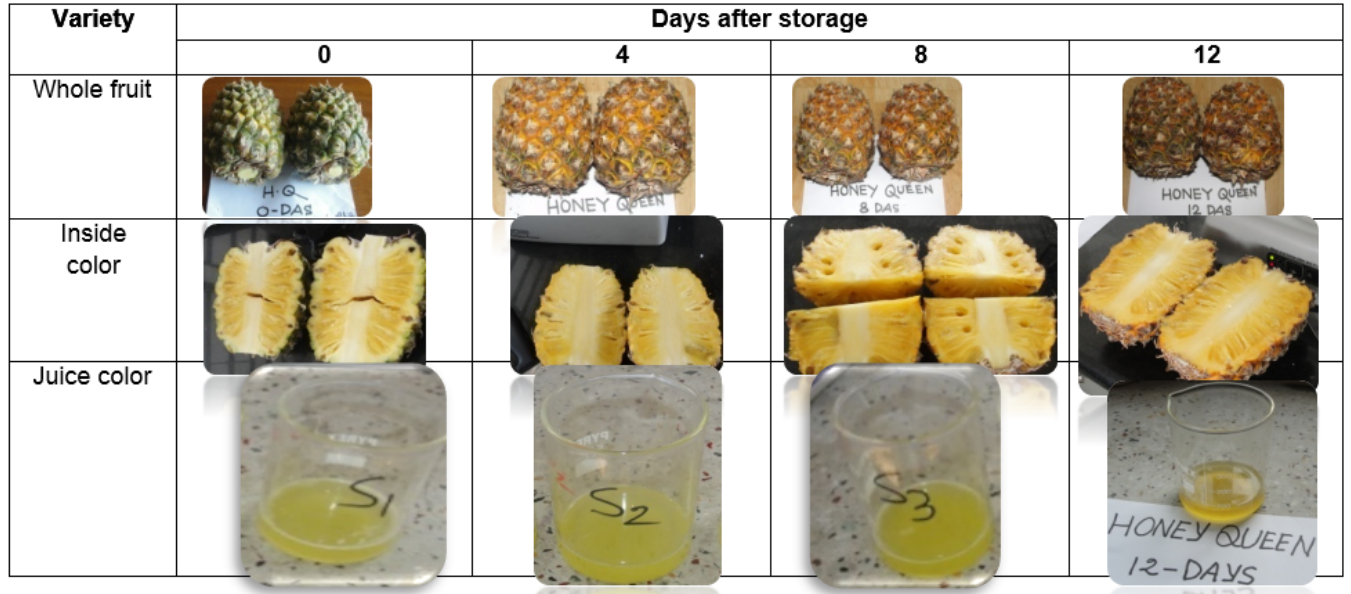

\section{Effects of chemical properties of fruits during storage period}

pH

It was observed that $\mathrm{pH}$ values show increase in trends with time. The $\mathrm{pH}$ values changes in the range of 4.31 to $4.38,4.28$ to $4.33,4.21$ to 4.32 and 4.29 to 4.36 for the varieties of H.Q, J.K, Asshini and Ghorashal, respectively.

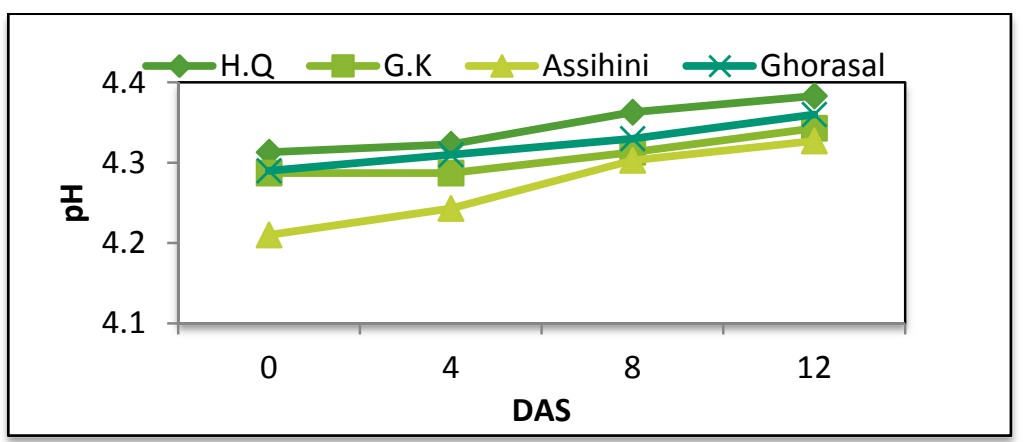

Figure 5. $\mathrm{pH}$ of different pineapple varietiesat different DAS

TSS

Figure 6 showed that the TSS of pineapple fruits was increased with the increased 0, 4, 8 and 12 days after storage. Among for variety H.Q. exhibits highest amount of TSS (14.26 to 15.96\%) following by Asshini (12.73 to $13.56 \%)$, G.K. (11.40 to $13.26 \%$ ) and Ghorashal (11.55 to $14.36 \%)$.TSS is one of the most important quality factors for most of the fruits and for pineapple; a TSS of 13.8 to $17.0 \%$ indicates the highest quality of fruits to attain the optimum harvesting stage (Morton, 1987). As a result, the increasing trend of percent total soluble solids contents of fruit during storage could be attributed mainly to the breakdown of starch into simple sugars during ripening along with a proportional increase in TSS and further hydrolysis decreased the TSS during storage. 


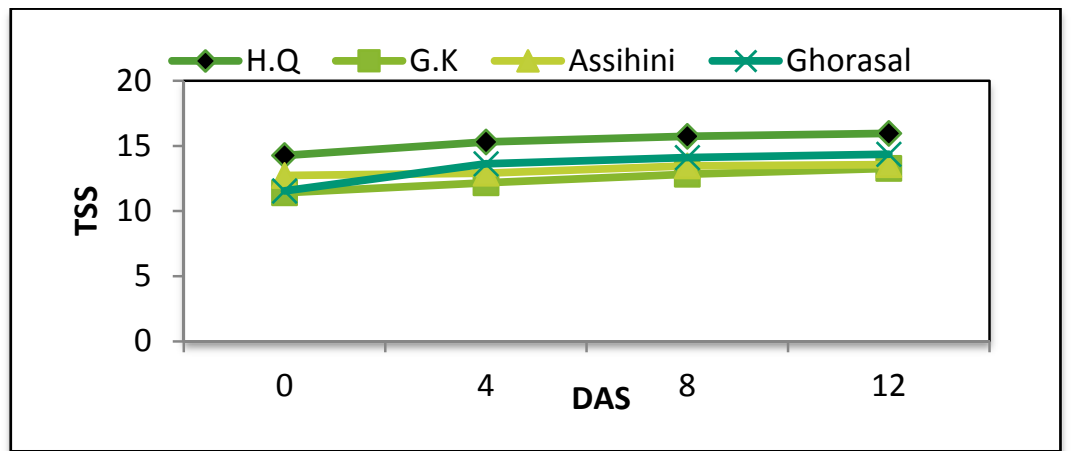

Titrable acidity

Figure 6. TSS content of different varieties of pineapple at different DAS

The Figure 7 showed that the titratable acidity is slightly decreased with increased the storage life. The values of titrable acidity for varieties are: Honey Queen: 0.49 to $0.41 \%$ with a mean value of $0.46 \%$ which was the maximum, Asshini: 0.68 to $0.62 \%$, Giant Kew: 0.62 to $0.54 \%$ and Ghorashal : 0.56 to $0.46 \%$ Singleton (1958) suggested that acid content increase during maturation in warm condition and also said that decreased in the titrable acidity of pineapple in acidity during the ripening of pineapple was due to the loss in the dominant citric acid.

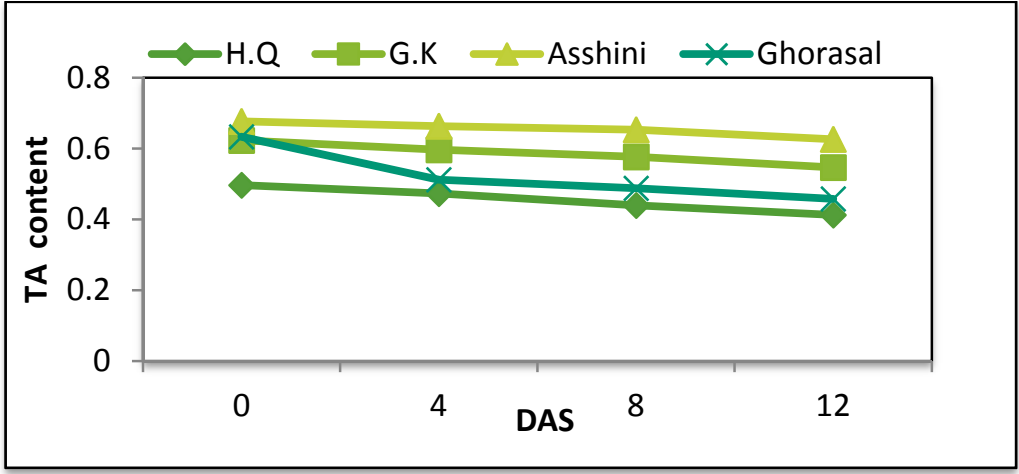

Figure 7. TA content (\%) of different varieties of pineapple at different DAS

\section{Sweetness index}

Figure 8 shown that the sweetness index increased with increase the storage time. The acidity was the highest in the fruits Asshini refers to Giant Kew while the soluble solids were the highest in the H.Q. variety. These results showed that the fruits H.Q. are sweeter than other varieties.

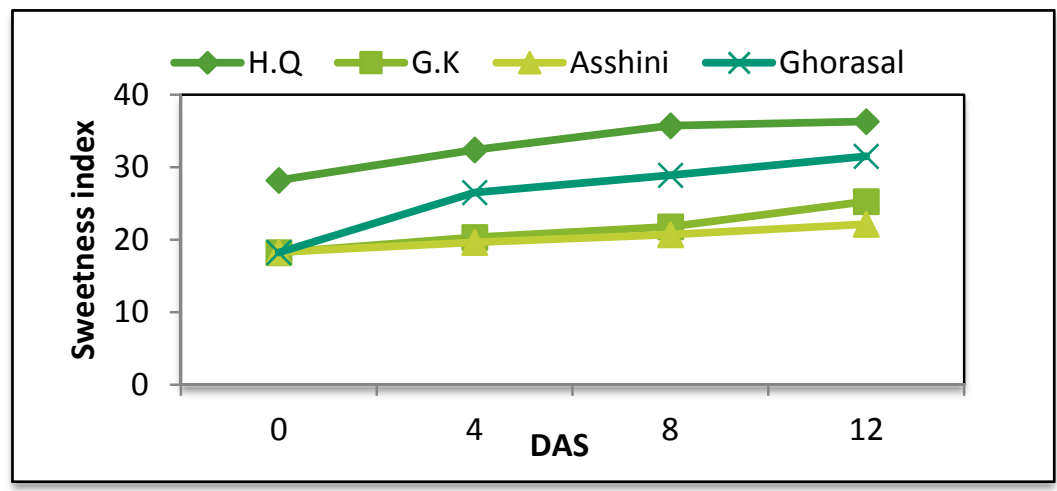

Figure 8. Sweetness index of different varieties of pineapple at different DAS 


\section{Vitamin C content}

It was observed that among the storage period (0, 4, 8 and 12 DAS), the ascorbic acid content in Honey Queen (14.2 to 8.73), Giant Kew (15.8 to 11.6), Asshini (15.5 to 10.9) and Ghorashal (14.70 to 9.89) were similar for the variety. Vitamin C content in the variety Giant Kew and Asshini are higher than that of Honey Queen and Ghorashal variety, indicating that Giant Kew and Asshini are slightly more acidic than Honey Queen and Ghorashal. Rashid (1987) reported that pineapple contains 10-25 mg/100 gm of vitamin C.

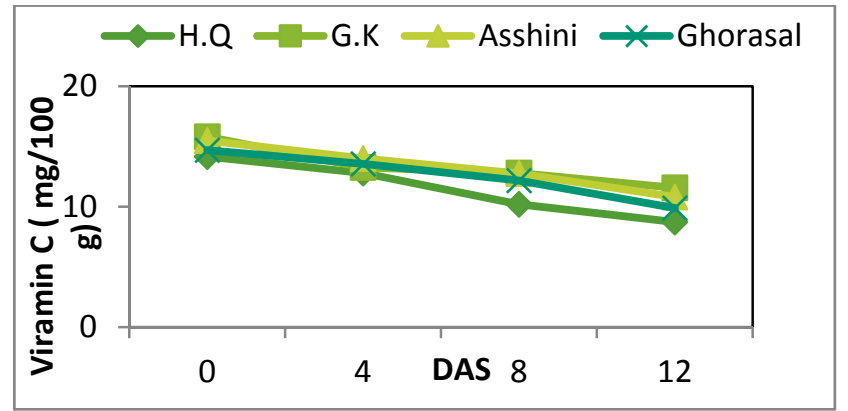

Figure 9. Vitamin $\mathrm{C}$ content of the different varieties of pineapple at different DAS

\section{Total sugar content}

It was shown that the total sugar gradually increased with increased during storage day (Fig. 10). Of the four varieties the Honey Queen (11.71 to $14.7 \mathrm{mg} / 100 \mathrm{gm}$ ) contains higher amount of total sugar than the Giant Kew (10.2 to $12.0 \mathrm{mg} / 100 \mathrm{gm})$,Asshini $(9.9$ to $11.5 \mathrm{mg} / 100 \mathrm{gm})$ and Ghorashal (11.55 to $13.20 \mathrm{mg} / 100$ gm) during storage periods. Amankwa (1995), Upadhayay and Tripathi (1985) observed that total sugar in the pineapple juice increased gradually with time which was similar trend as found in the present study.

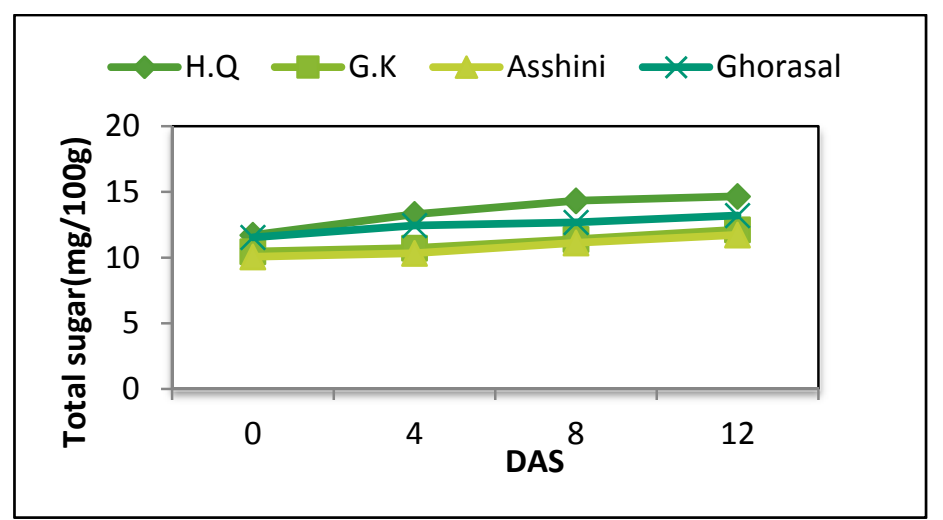

Figure 10. Total sugar content of different varieties of pineapple at different DAS

\section{Sensory evaluation}

Table 5. Comparison of different varieties of pineapple under sensory evaluation

\begin{tabular}{|lllll|}
\hline Characteristics & \multicolumn{3}{c|}{ Different varieties of pineapple } \\
\cline { 2 - 5 } (observed at12 DAS) & Honey Queen & \multicolumn{1}{c|}{ Giant Kew } & Asshini & Ghorashal \\
\hline Appearance & fairly good & slightly bad & acceptable & fairly good \\
Firmness & very firm & fairly firm & slightly firm & firm \\
Sweetness & very strong & fair & fair & strong \\
Tartness & strong & fair & fair & strong \\
Overall acceptability & likes slightly & accepts & accepts & likes slightly \\
\hline
\end{tabular}


Table 4. Effects of chemical properties of different varieties of pineapple during day after storage.

\begin{tabular}{|c|c|c|c|c|c|c|c|c|c|c|c|c|c|c|c|c|}
\hline \multirow[t]{3}{*}{ Characteristics } & \multicolumn{16}{|c|}{ Varieties of pineapple } \\
\hline & \multicolumn{3}{|c|}{ Honey Queen } & \multicolumn{4}{|c|}{ Giant Kew } & & \multicolumn{4}{|c|}{ Asshini } & \multicolumn{4}{|c|}{ Ghorashal } \\
\hline & D0 & D4 & D8 & D12 & D0 & D4 & D8 & D12 & D0 & D4 & D8 & D12 & D0 & D4 & D8 & D12 \\
\hline $\mathrm{pH}$ & 4.31 & 4.32 & 4.36 & 4.38 & 4.28 & 4.28 & 4.31 & 4.34 & 4.21 & 4.24 & 4.30 & 4.32 & 4.29 & 4.31 & 4.33 & 4.36 \\
\hline TSS & 14.2 & 15.3 & 15.7 & 15.9 & 11.4 & 12.1 & 12.8 & 13.2 & 12.7 & 12.9 & 13.46 & 13.56 & 11.5 & 13.63 & 14.10 & 14.36 \\
\hline TA & 0.49 & 0.47 & 0.44 & 0.41 & 0.62 & 0.59 & 0.57 & 0.54 & 0.67 & 0.66 & 0.653 & 0.626 & 0.56 & 0.512 & 0.488 & 0.458 \\
\hline $\mathrm{SI}$ & 28.2 & 32.3 & 35.7 & 36.3 & 18.2 & 20.3 & 21.7 & 25.2 & 18.2 & 19.6 & 20.72 & 22.15 & 20.2 & 26.50 & 28.89 & 31.50 \\
\hline TS & 11.7 & 13.3 & 14.3 & 14.6 & 10.4 & 10.7 & 11.4 & 12.1 & 10.1 & 10.3 & 11.13 & 11.73 & 11.5 & 12.44 & 12.68 & 13.20 \\
\hline RS & 8.26 & 9.73 & 10.2 & 10.7 & 6.76 & 7.70 & 8.83 & 9.16 & 6.23 & 7.50 & 8.467 & 8.867 & 7.40 & 9.234 & 9.850 & 10.20 \\
\hline VC & 14.2 & 12.8 & 10.2 & 8.73 & 15.8 & 13.3 & 12.8 & 11.5 & 15.5 & 14.0 & 12.76 & 10.80 & 14.7 & 13.56 & 12.17 & 9.89 \\
\hline
\end{tabular}

Table 4 shows the chemical values of different varieties of pineapple fruits are changed during different storage time. The chemical properties such as pH, TSS, SI, TS, RS of H.Q., G.K., Asshini and Ghorashal varieties are increased during increased from starting day to 12 DAS which are almost similar to the level for pineapple fruit. The TA and VC of different varieties of pineapple shows that the chemical values decreased during storage time. 
The color, firmness, sweetness, appearance, sweetness and tartness, overall acceptability were recorded by sensory evaluation. Sensory analysis was carried out by a panel of six non- trained assessors, recruited among students, Professors and employees of BSMRAU, Gazipur. Assessors evaluated the pineapple fruit quality using sorting preference tests and hedonic scale. Each assessor evaluated three sample of each cultivar, previously randomized to avoid position bias and presented in recipients with lids, coded with random three symbols. The sensory evaluation test was done to determine the quality and acceptance of the pineapple fruits derived from four varieties of pineapple. The results from the taste panel are shown in Table 5. The average score by the taste panelists showed an acceptability of the fruits appearance.

Table 6. Effects of shelf life of pineapple during storage

\begin{tabular}{|cccccc|}
\hline Date & Whole fruit, $\mathbf{k g}$ & \multicolumn{2}{c}{ Firmness, $\mathbf{N} / \mathbf{m}^{\mathbf{2}}$} & \multirow{2}{*}{ Edible portion, $\mathbf{k g}$} & \% edible portion \\
\cline { 3 - 4 } & & Outside & Inside & & \\
\hline 0 DAS & 0.915 & 0.270 & 0.077 & 0.560 & 61.2 \\
4 DAS & 0.795 & 0.210 & 0.075 & 0.495 & 62.3 \\
8 DAS & 0.830 & 0.227 & 0.075 & 0.538 & 64.8 \\
12 DAS & 0.860 & 0.220 & 0.095 & 0.547 & 63.7 \\
\hline
\end{tabular}

Firmness of tissue makes sure the quality of fruits at storage condition. The fruits lost its firmness with increase in storage period. From Table 6, it was shown that the firmness of outside and inside of pineapple ranges are 0.210 to $0.270 \mathrm{~N} / \mathrm{m} 2$ and 0.075 to $0.095 \mathrm{~N} / \mathrm{m} 2$ respectively. It was observed that the firmness of pineapple are slightly changed because when their moisture percentages are decreased during storage and then unchanged their inside and outside firmness.

\section{CONCLUSION}

The present research was conducted on physico-chemical characteristics changes, shelf life and quality of pineapple through various experimental analyses of pineapple varieties during the different storage period. The data were recorded on color change, firmness, moisture content, TSS, reducing sugar, non-reducing sugar, total sugar, titratable acidity, TSS, ascorbic acid, $\mathrm{pH}$, edible portion and shelf life. From the physical analysis peel color of pineapple was matured green at the preliminary time of experiment. Peel color and firmness changes were significantly influenced during storage. Moisture content of pineapple fruits was significantly affected during storage. From the analysis it is found that the moisture content, titratable acidity, Vitamin $\mathrm{C}$ were decreased during storage and the properties such as ash (\%), edible portion (\%), $\mathrm{pH}, \mathrm{TSS}$, sweetness index, total sugar and reducing sugar were increased during storage.

The firmness of pineapple fruit was measured both in outside and inside to be 0.21 to $0.27 \mathrm{~N} / \mathrm{m}^{2}$ and 0.075 to $0.095 \mathrm{~N} / \mathrm{m}^{2}$, respectively. It might be concluded that storage of harvested pineapple could be extended up to twelve days after harvesting for its improved quality except vitamin $\mathrm{C}$ which was higher during consumption right after harvest.

\section{RECOMMENDATIONS}

- Different processed product should be prepared from different varieties of pineapples and their comparison study should be carried out.

- Imparting short training for the farmers to acquaint with varieties of pineapple, modern technology of cultivation of pineapple and storage facilities. 


\section{REFERENCES}

1. Ahmaed K and Rahman MS, 1974. Edible portion and non-edible wastes of some fruits of Bangladesh. Bangladesh Horticulture, 2: 38-41.

2. Amankwa APA,Martin PP and Hugon R,1995. Effect of time of harvest on the fruit. Quality characteristics of pineapple in two areas of Southern Ghana.Acta Horticulture, 425: 531-538.

3. AOAC, 1990. Official Methods of Analysis. 15th ed. Association of Official Analytical chemist, Washinton D.C. P.1005.

4. Das R and Medhi G, 1996. Physico-chemical changes of pineapple fruits under certain post-harvest treatments. South Indian Horticulture Journal, 44: 5-7.

5. Hassan MK, 1980. Final Report of USAID and EC funded project (jointly implemented by FAO) entitled "Postharvest Loss Assessment: A Study to Formulate Policy for to Loss Reduction of Fruits and Vegetables and Socio Economic Uplift of the Stakeholders". P.50-53.

6. Lane $\mathrm{J} \mathrm{H}$ and Eynon L, 1923. Method for determination of reducing and non- reducing sugar. Journal of the Chemical Society, India, 42: 32-37.

7. Lodh SB, Diwaker NG, Chadha KL, Melanta KR and SelvarajY, 1973. Biochemical Changes associated with growth and development of pineapple fruits var. Kew. III. Indian Journal of Horticulture, 30: 381-383.

8. Morton JF, 1987. Fruits of Warm Climates. Miami, USA. pp. 18-22.

9. Ranganna S, 1994. Manual of Analysis of Fruit and Vegetable Products. Tata Mc Graw-Hill Publishing Company Limited, New Delhi, p. 634.

10. Rohrbach KG and Pall DJ, 1982. Post-harvest diseases of pineapple. Acta horticulture, 269,503-08.

11. Singleton VL, 1958. A test for the degree of bruising of pineapple flesh. Pineapple Res. Inst. Hawaii, Honolulu. Pineapple Res. Inst. News, 6:111-114 (Private document).

12. The Daily Star, 2014.W.W.W. The daily star net accessed on 22.06.2014

13. Upadhyay NP and Tripathi BM, 1985. Postharvest changes during storage and ripening of mango (Mangiferaindica 1.) fruit. Progressive Horticulture, 17: 25-27.

14. USDA, 2008.United States Department of Agriculture, Food Security in the United States Measuring Household Food Security. 